\title{
Quantitative and Qualitative Assessment of Mycological Air Pollution in a Dormitory Bathroom with High Humidity and Fungal Stains on the Ceiling a Case Study
}

\author{
Agata Piecuch, Rafal Ogórek* \\ Department of Mycology and Genetics, Institute of Genetics and Microbiology, University of Wrocław, \\ Przybyszewskiego Street 63/77, 51-148 Wrocław, Poland
}

Received: 14 March 2020

Accepted: 6 July 2020

\begin{abstract}
The development of indoor molds is mainly connected to the room conditions, like air humidity, temperature or $\mathrm{pH}$. The sanitary rooms, usually with elevated dampness, are a good environment for fungal growth and should be monitored for fungal concentration due to the risk of an elevated exposure to fungal allergens and mycotoxins. In the present work the diversity and the concentrations of fungal pollutants in the dormitory bathroom of Polish University was evaluated for both the ceiling and the air. The results showed that Cladosporium cladosporoides was the only species found on the dark stains on the ceiling, but in the air the variety of fungi was higher, with a total of 6 species: Aspergillus flavus, A. niger, C. cladosporioides, Fusarium poae, Penicillium chrysogenum and Rhizopus nigricans. The increased concentration of $A$. niger and C. cladosporoides in the air suggests further control of the air pollution in order to avoid excessive exposure to mycotoxins and allergens. Moreover, the concentration of airborne fungi inside the facility exceeded some standards of fungal air contamination stated as dangerous for human health. Our study allows for unambiguously identifying isolated fungi and develop recommendations, to prevent the present outbreak of fungi as well as in the future.
\end{abstract}

Keywords: indoor molds, bio-aerosol, sanitary rooms, public health

\section{Introduction}

Bathrooms, as sanitary rooms with high air humidity, have perfect conditions for microbial growth [1]. The ambient temperature and the level of dampness promote the development of microscopic fungi,

*e-mail: rafal.ogorek@uwr.edu.pl,rafal-ogorek@wp.pl especially molds. The higher humidity is often caused by lower air flow due to airproof windows, impaired ventilation, or thermo modernization, which leads to the development of fungal stains on walls but also to the elevated amount of fungal particles in the air [2].

The indoor molds found in bathrooms not only are a cause of fungal decay of the building but also may be connected to the serious health issues [3]. It should be recalled that already Hippocrates mentioned in the 
Corpus Hippocraticum manuscript that some of the air components can be the cause of human illness [4]. Therefore, fungal spores, as a part of bioaerosols, play a role in respiratory diseases but their pathological effects in humans may also be connected with the production of mycotoxins. Currently known mycotoxins are classified into groups based on their activity: mutagenic, carcinogenic and teratogenic, and are produced by molds commonly found outdoors and indoors, like Aspergillus sp., Penicillium sp. or Fusarium sp. [3].

Another clinical aspect of indoor fungi are allergic reactions to fungal particles in bio-aerosol. Allergens produced by various molds (Alternaria, Aspergillus, Cladosporium, Mucor, Penicillium, Rhizopus) are of great medical significance since they can cause fungal sensitization (elevated $\operatorname{IgE}$ ), but some of them (mainly Aspergillus) might be the cause of fungal allergy, resulting in severe fungal asthma [5]. The exposure to the fungal particles (mycotoxins and allergens) is dependent on the fungal concentration in the facility, thus the number of fungi should be monitored [1].

Therefore, poor indoor air quality of buildings can affect the deterioration of the health of residents such as skin and respiratory problems, poisoning, malaise and general weakness [6]. It is estimated that this problem can affect up to 3 billion people worldwide, and in 1983 the term "sick building syndrome" (SBS) was introduced to describe the situation where a building affects human health [7]. Mould growth and its secondary metabolites is the phenomena which can cause SBS, and their spores can constitute up to $70 \%$ of all bioaerosol pollution of indoor air $[8,9]$.

The aim of this work was to evaluate fungal pollution both on the ceiling and in the air in the dormitory bathroom in Wrocław, Poland, as an example of a public sanitary room with high air humidity. The study allowed us to identify fungal isolates and to quantify their number in the air.

\section{Experimental}

\section{Fungal Isolation}

The samples were collected from the dormitory bathroom in Wrocław (University of Wrocław), Poland $\left(3.6 \mathrm{~m}^{2}\right)$ with no windows or air-conditioning (only with ventilation grating) in the spring. The ceiling, covered with white, acrylic paint, displayed visible black spots (Fig. 1). Paint fragments with hyphae were scraped with a sterile scalpel or swabbed with a sterile cotton swab and placed on PDA (Potato Dextrose Agar, Biocorp) for 2-14 days at $24 \pm 0.5^{\circ} \mathrm{C}$. The analysis were performed using streaking or serial dilution method on PDA.

Samples were also collected from the air filling the facility using the Koch sedimentation method [10]. Open plates $(\varnothing=90 \mathrm{~mm})$ with PDA was placed one meter from the floor and exposed for 10, 20 and
$30 \mathrm{~min}$ (each time in three replicates). Plates were then incubated for 2-14 days at $24 \pm 0.5^{\circ} \mathrm{C}$ and colony forming units in $1 \mathrm{~m} 3$ of air $\left(\mathrm{CFU} / \mathrm{m}^{3}\right)$ was estimated. Fungi were inoculated on fresh PDA for further identification.

\section{Species Identification}

Macroscopic and microscopic appearance, as well as and growth rate, were used for identification of collected fungi according to diagnostic monographs [11-14]. Additionally, the phenotypes of fungi were compared with the strains from Ogórek's collection (Department of Mycology and Genetics, Institute of Genetics and Microbiology, University of Wrocław, Wrocław, Poland), which were identified using phenotypic and molecular studies and their internal transcribed spacer sequences were identified by the National Center for Biotechnology Information (Bethesda, Rockville, MD, USA).

Fungal colonies on PDA were photographed with a Nikon cooplix S3700. Fungal samples (14-day old on PDA) were stained with LPCB (Lactophenol Cotton Blue, Sigma-Aldrich) and observed in the Axio Image. M1 (Zeiss) microscope.
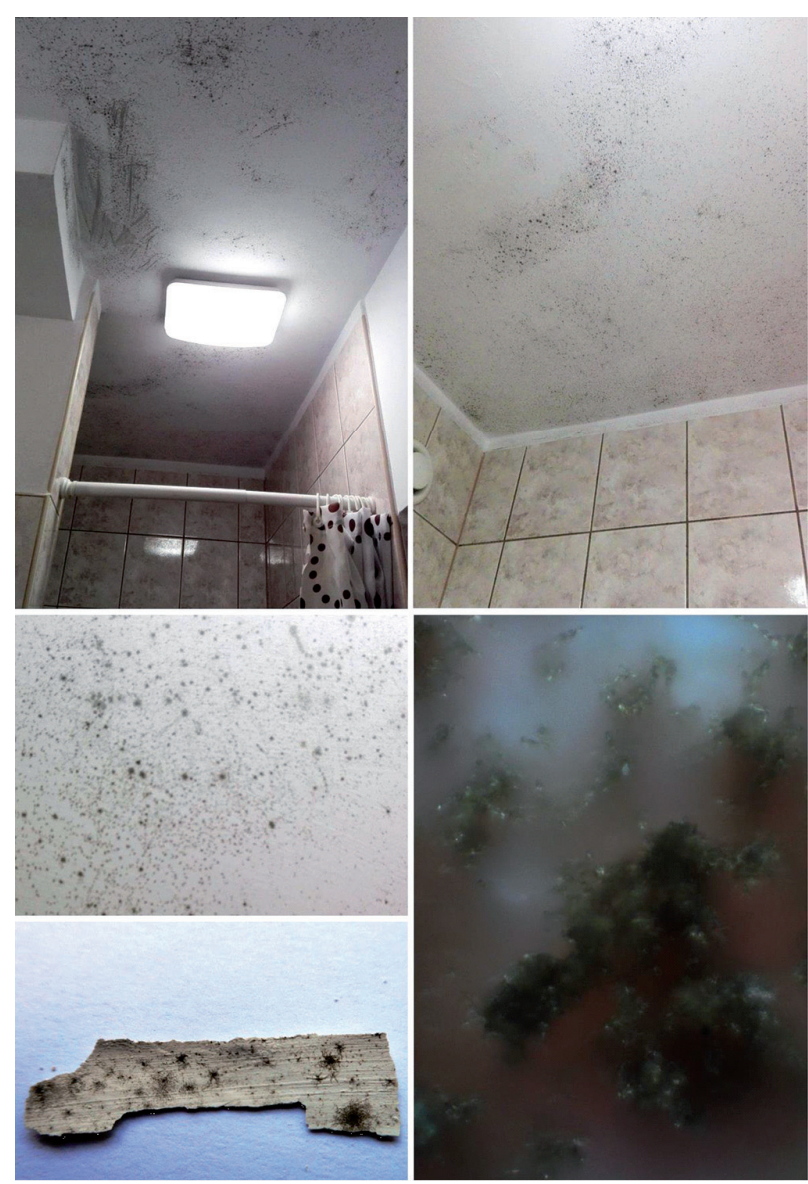

Fig. 1. The dark stains covering bathroom ceiling in the studied facility - the samples were collected from the paint scrapings. 


\section{Data Analyses}

The data were subjected to statistical analysis using the Statistica 13.3 package (StatSoft Polska Sp. z o.o., Kraków, Poland). For this purpose, we used one-way analysis of variance (ANOVA) and the Tukey HSD (honest significant difference) test at $\alpha \leq 0.05$.

\section{Results and Discussion}

We used the most popular method to determine the microbiological quality of the air, which is the culturebased analysis. In this method, the type of culture medium and technique (passive or active) used to collect biological material from the air are very important [15]. According to literature, Sabouraud agar medium is most suitable for isolation of a large spectrum of fungal species from the environment, and PDA medium demonstrates comparable efficacy as Sabouraud agar [16-18]. Therefore, we used this medium in our study. On the other hand, the passive technique so-called the Koch sedimentation method was used to catch fungal spores and their other propagation structures from the air. This technique, compared to the active methods, involving the mechanical catching of airborne microorganisms (filtration, collision, centrifugal) has several disadvantages and advantages. For many particles, the assumption of this method does not work, because the rate of deposition of particles depends on many factors, such as size, weight, electrostatic charge, humidity, air movement. Therefore, the smallest components of bioaresol are not detected that settle very slowly or do not sediment at all. The sedimentation method can only be used in facilities where there is no air movement [19]. On the other hand, this method is simple, fast and low cost, due to the lack of specialized air samplers that are used in the collision method [15].

Fungal development inside the buildings depends on various factors, such as air humidity, temperature, ventilation or type and properties of building materials [20]. Sanitary rooms exhibit higher humidity, which facilitates growth of fungi. The samples collected from paint scrapings and facility air contained 1 and 6 isolates respectively, which differed in the colony morphology on PDA (Fig. 2). Microscopic analysis confirmed that isolated fungi belonged to 5 different genera: Aspergillus, Cladosporium, Fusarium, Penicillium and Rhizopus (Fig. 2a-2f).

Paint scrapings contained fungi belonging only to the C. cladosporioides. Thus fungi are reported as the most frequent isolates from building interiors, including bathrooms. Their natural environment are plant remains, but once in the building these fungi might secondarily colonize paint, wood or wallpapers $[1,21]$. C. cladosporoides is a heterogenous complex of many distinct species, including strains of clinical relevance (e.g., C. anthropophilum). Fungi from this genus are
Table 1 . The amount of fungi isolated from the facility air.

\begin{tabular}{|c|c|c|}
\hline Fungal culture & \multicolumn{2}{|c|}{$\begin{array}{c}\text { Fungal } \\
\text { concentration } \\
\left(\mathrm{CFU} / \mathrm{m}^{3}\right)\end{array}$} \\
\hline Aspergillus flavus Link & 8.7 & $\mathrm{c}^{* *}$ \\
\hline Aspergillus niger Tiegh. & 273.3 & $\mathrm{~b}$ \\
\hline $\begin{array}{c}\text { Cladosporium cladosporioides (Fresen.) } \\
\text { G.A. de Vries* }\end{array}$ & 392.1 & $\mathrm{a}$ \\
\hline Fusarium poae (Peck) Wollenw. $^{*}$ & 6.1 & $\mathrm{c}$ \\
\hline Penicillium chrysogenum Thom & 28.4 & $\mathrm{c}$ \\
\hline Rhizopus nigricans Ehrenb. & 7.0 & $\mathrm{c}$ \\
\hline Total & \multicolumn{2}{|c|}{715.7} \\
\hline
\end{tabular}

*species isolated also from paint samples

** assignment of the same letter means lack of statistical significance (Tukey`a HSD test, $\alpha \leq 0.05$ )

mostly associated with allergies and superficial lessions, rarely with invasive infections. The latter include central nervous system and intrabronchial infections, mainly in immunocompromised patients [22, 23].

Small rooms, usually like bathroom, often without windows, drying rooms where a lot of wet laundry is dried, are particularly exposed to the development of fungi and moulds. This is usually accompanied by an unpleasant smell. The main reason for this is usually the excessive humidity in such rooms [6]. The maximum dampness is usually found in buildings without proper thermal insulation or in newly constructed facilities, or poor or lack of ventilation [2]. Therefore, first of all, it is necessary to find the source of the dampness and decide how to remove the excess of it. According to the literature, definitely, we should mainly focus on the use of an efficient ventilation system and the frequent airing of the rooms. Dehumidifiers can also be of assistance here, especially in smaller rooms [24]. People who cannot prevent the occurrence of the mould problem, they need to resort to chemical agents, special plasters and anti mould paint or major flat renovation. Because fungi are very difficult to get rid of if they have grown deep into various materials, including plasters on the walls and ceilings of the rooms [25, 26]. It is also possible to use physical methods to preventing and combating attacks of fungus as well as other harmful living organisms (e.g. longicorn beetles and wood worm) in existing building structures, e.g. by using lectromagnetic energy which involves heating the attacked areas to temperatures lethal to living organisms [27].

Overall, the concentration of fungal spores in the tested room was of $715.7 \mathrm{CFU} / \mathrm{m}^{3}$. According to some standards of fungal air contamination (the World Health Organization or the European Confederation Commission) the mycological quality of air in the investigated sites does not pose a threat to people with an unimpaired immune system [24]. However, according 
a)
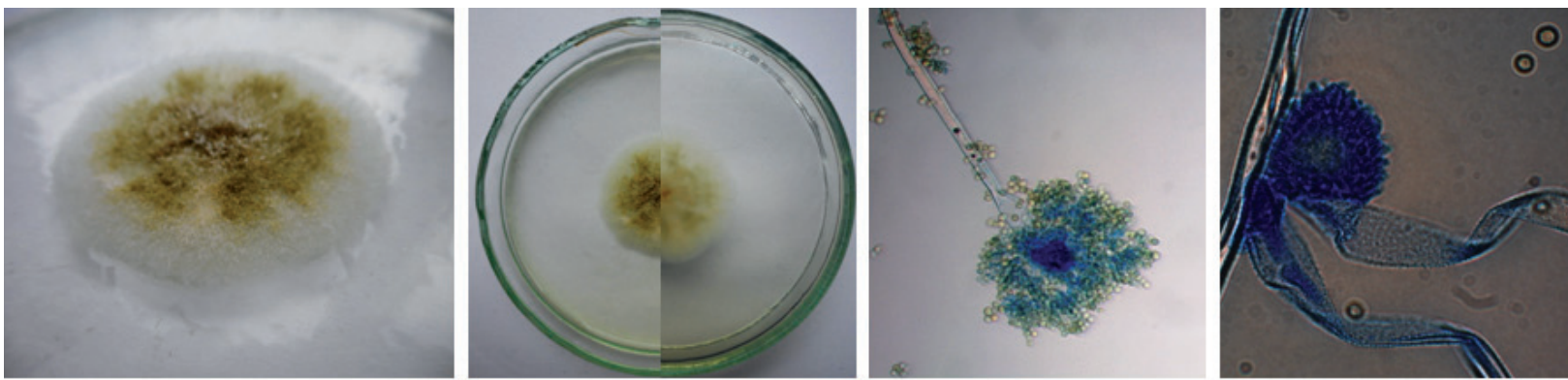

b)
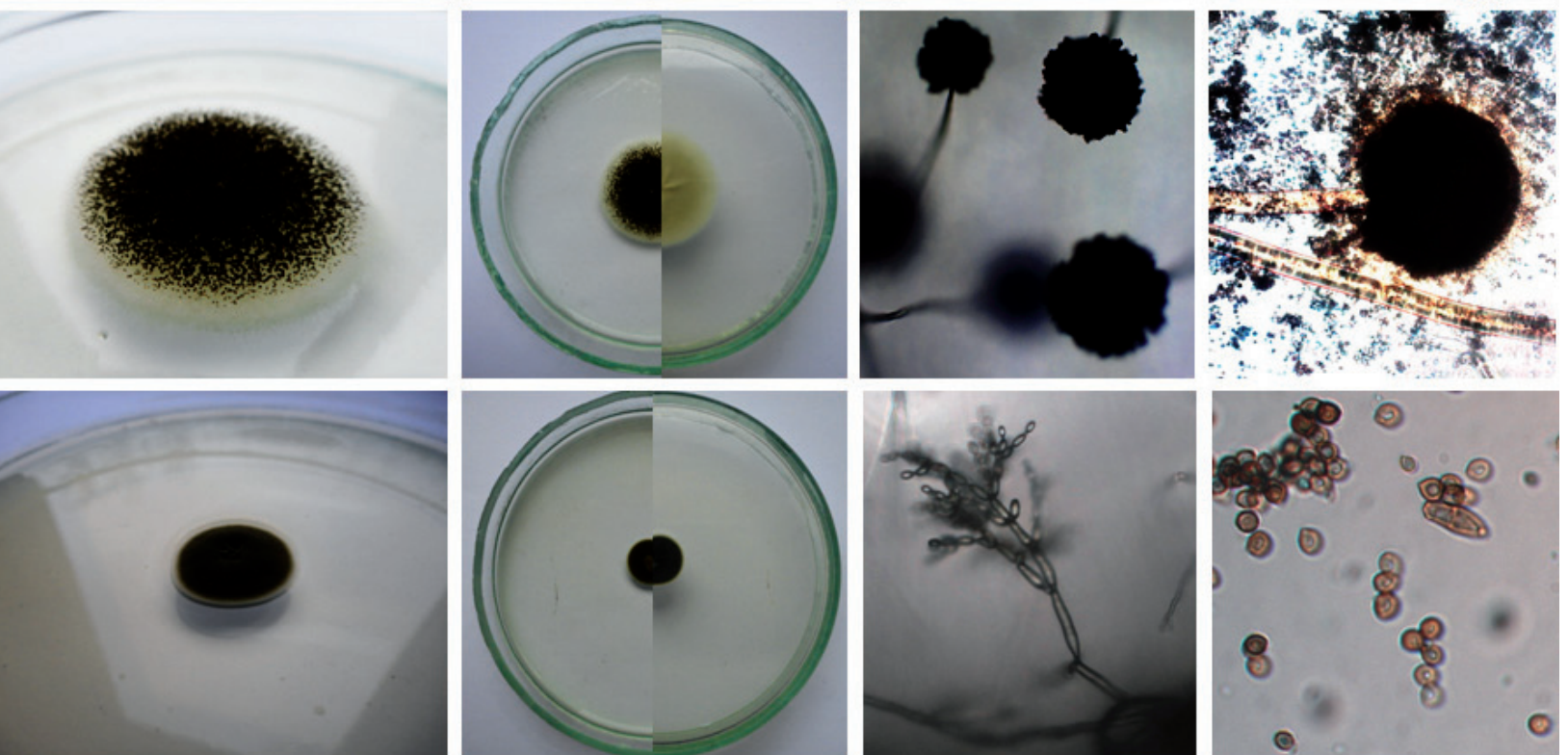

d)
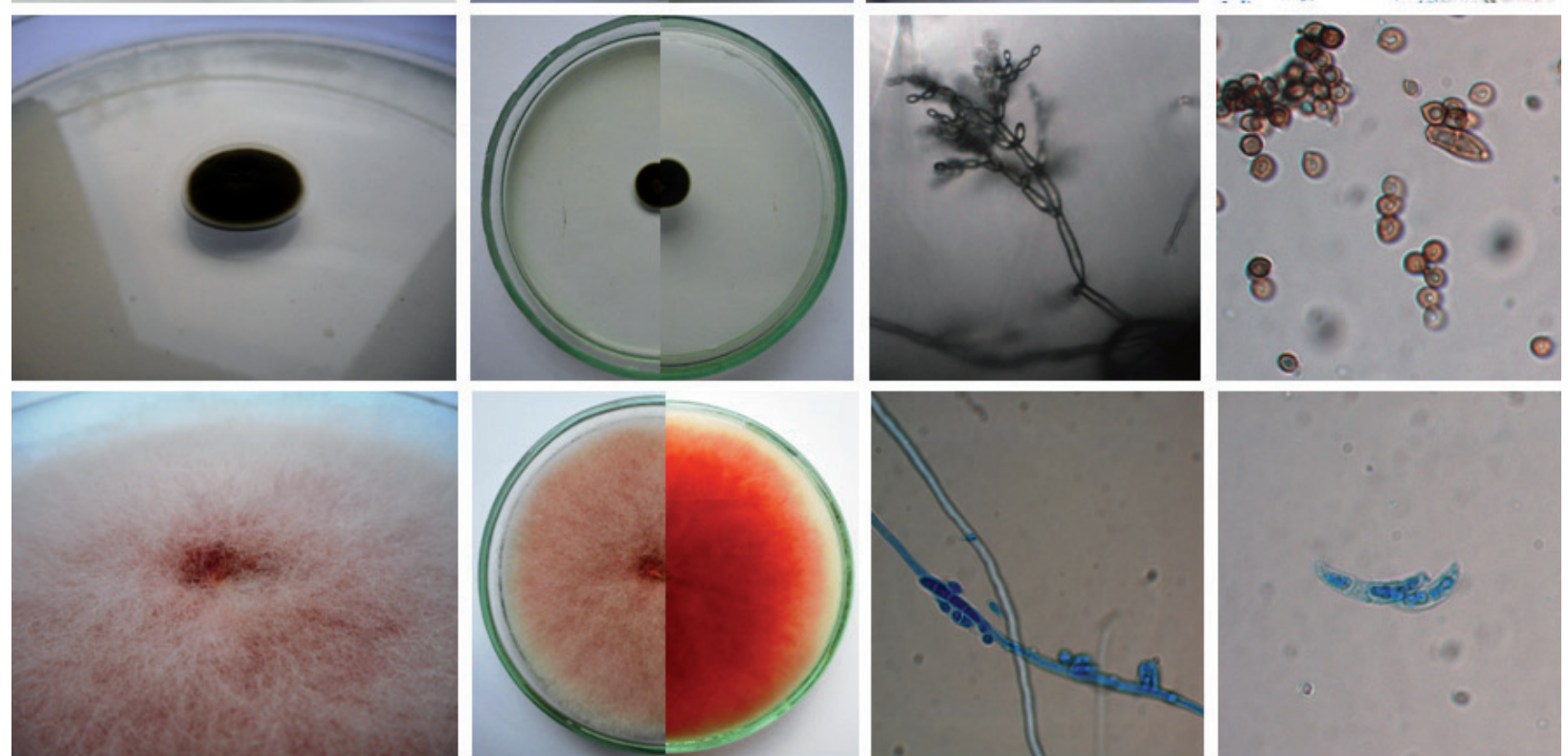

e)
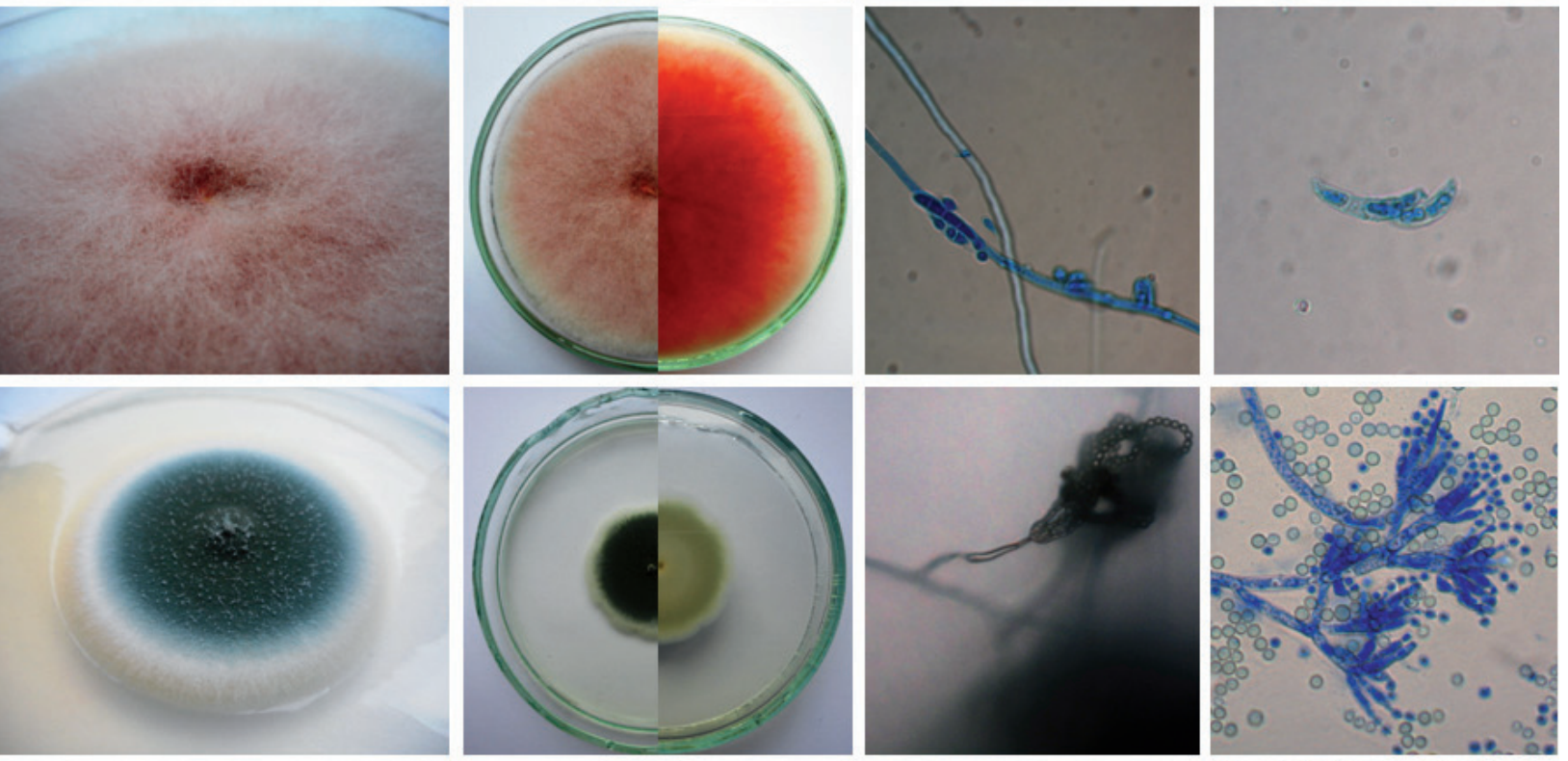

f)
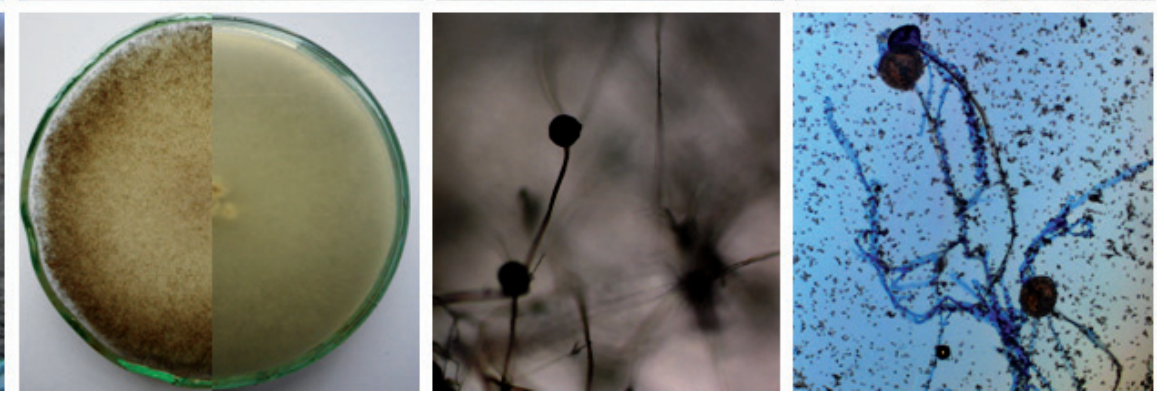

Fig. 2. Macroscopic (panel 1 and 2) and microscopic (panel 3 and 4) images of fungi isolated from the facility after 14 days of incubation at $24 \pm 0.5^{\circ} \mathrm{C}$ on PDA medium: a) A. flavus, b) A. niger, c) C. cladosporioides, d) F. poae, e) P. chrysogenum, f) $R$. nigricans. 
to the American Industrial Hygiene Association and Swedish requirements, the concentration of airborne fungi should not be higher than 500 and 300 spores per $\mathrm{m} 3$ for residential buildings, respectively [28, 29]. The fungal CFU number in the studied facility significantly exceeded those values $(\mathrm{p}<0.05)$, thus should be further monitored to avoid exposure to mycotoxins produced by molds.

Among the six airborne fungal species, $C$. cladosporoides dominated in the air samples $\left(\mathrm{P}_{\text {C. cladosporioides, A. niger }}=0.000159\right)$ at the concentration of $392.1 \mathrm{CFU} / \mathrm{m}^{3}$. On the other hand, species such as A. flavus, $F$. poae, $P$. chrysogenum and $R$. nigricans were the least isolated airborne fungi $\left(\mathrm{P}_{\text {A.niger.P. chrysogenum }}=0.000162\right)$ and their spores did not exceed $10 \mathrm{CFU} / \mathrm{m}^{3}$ with the exception of $P$. chrysogenum, which CFU $/ \mathrm{m}^{3}$ number was 28.4 (Table 1, Fig. 2a-2f). Aspergillus, Cladosporium and Penicillium are the most common components of bio-aerosols [30]. Some of these genera are known producers of various mycotoxins (e.g., ochratoxin A or patulin) and elevated exposure to such compounds might constitute a significant health issue (like nephrotoxicity or mutagenicity) [31]. Moreover, the inhalation of airborne particles containing conidia of these fungi especially in room with greater dampness, can result in various respiratory symptoms e.g., asthma, bronchitis or allergic rhinitis [32]. It should be also stressed out that Cladosporium sp. are classified as the inducers of IgE-mediated sensitization and the source of allergic rhinitis or asthma. However, ca. 2800 spores per liter is necessary to induce symptoms of allergic respiratory system disease in most patients with hypersensitivity to these allergens [33, 34]. Thus, the amount of Cladosporium fungi in studied bathroom does not constitute a significant allergic risk to residents. Nevertheless, the control of the concentration of indoor molds is ery important and should be systematically conducted [1].

\section{Conclusions}

In summary, elevated amount of molds were found in the dormitory bathroom in Wrocław (Poland). The visible black spots on the ceiling were produced by Cladosporium cladosporioides. In turn, the concentration level of fungal spores did exceed some standards of fungal air contamination stated as dangerous to the human health. Overall, due to the high air humidity caused by the poor ventilation, the amount of the fungi should be monitored to prevent excessive exposure to the spores and the mycotoxins produced by indoor molds. Moreover, we recommend removing the surface layer of plaster, cleaning the surfaces and carrying out the disinfection process three times using commercially available fungicides, with intervals of several days between individual treatments, which will ensure that even the most resistant mycelium structures (e.g., spores, conidia, chlamydospores or arthrospores) have been eliminated. Then, we recommend using plaster with increased alkalinity and anti mold paint. In order to avoid a similar problem in the future, it was also recommended to apply the forced air circulation in the room by using a fan for ventilation. Finally, our recommendations allowed us to resolve a pressing problem and effectively secure the dormitory bathroom for the future.

\section{Conflict of Interest}

The authors declare no conflict of interest.

\section{References}

1. OGÓREK R., PLĄSKOWSKA E., KALINOWSKA K., FORNALCZYK P., MISZTAL A., BUDZIAK J. The analysis of mycological air pollution in selected rooms of student hostels. Mikologia Lekarska, 18 (4), 201, 2011.

2. MENDELL M.J., MACHER J.M., KUMAGAI K. Measured moisture in buildings and adverse health effects, A review. Indoor Air, 28 (4), 488, 2018.

3. OMOTAYO O.P., OMOTAYO A.O., MWANZA M., BABALOLA O.O. Prevalence of mycotoxins and their consequences on human health. Toxicological Research, 35 (1), 1, 2019.

4. MAMMAS I.N., SPANDIDOS D.A. Paediatric virology in the hippocratic corpus, Experimental and Therapeutic Medicine, 12, 541, 2016.

5. AGARWAL R., SEHGAL I.S., DHOORIA S., AGGARWAL A.N. Challenging cases in fungal asthma. Medical Mycolology, 57 (2), S110, 2019.

6. WAHAB A.N.S., KHAMIDI M.F., ISMAIL M.R. An Investigation of mould growth in tropical climate buildings. 2013 IEEE Business Engineering and Industrial Applications Colloquium (BEIAC), Langkawi, Malaysia, pp. 316-321, 2013.

7. WHO. Indoor Air Pollutants, exposure and health effects. WHO EURO Reports and studies. Copenhagen, World Health Organization. Report No 1983, 78, 1983.

8. BRICKUS L.S.R., SIQUEIRA L.F.G., AQUINO NETO F.R., CARDOSO J.N. Occurrence of airborne bacteria and fungi in bayside offices in Rio de Janeiro, Brazil, Indoor and Built Environment, 7, 270, 1998.

9. REYNOLDS S.J., BLACK D.W., BORIN S.S., BREUER G., BURMEISTER L.F., FUORTES L.J, SMITH T.F., STEIN M.A., SUBRAMANIAN P., THORNE P.S., WHITTEN P. Indoor environmental quality in six commercial office buildings in the Midwest United States. Applied Occupational and Environmental Hygiene, 16, 1065, 2011.

10. WIEJAK A. The assessment of air contamination with the mould fungi spores as an essential factor of mycological report. Prace Instytutu Techniki Budowlanej, 3, 3, 2011 [In Polish].

11. SEIFERT K. Fuskey, Fusarium interactive key. Agriculture and Agri-Food, Canada, 1996.

12. BENSCH K., BRAUN U., GROENEWALD J.Z., CROUS P.W. The genus Cladosporium. Studies in Mycology, 72 (1), 1-401, 2012. 
13. SAMSON R.A., VISAGIE C.M., HOUBRAKEN J., HONG S.B., HUBKA V., KLAASSEN C.H., PERRONE G., SEIFERT K.A., SUSCA A., TANNEY J.B., VARGA J., KOCSUBÉ S., SZIGETI G., YAGUCHI T., FRISVAD J.C. Phylogeny, identification and nomenclature of the genus Aspergillus. Studies in Mycology, 78, 141, 2014.

14. VISAGIE C.M., HIROOKA Y., TANNEY J.B., WHITFIELD E., MWANGE K., MEIJER M., AMEND A.S., SEIFERT K.A., SAMSON R.A. Aspergillus, Penicillium and Talaromyces isolated from house dust samples collected around the world. Studies in Mycology, 78, 63, 2014

15. OGÓREK R., LEJMAN A. Speleomycological research in the selected objects of underground Riese complex (Sowie Mountains, Lower Silesia, Poland). Postepy Mikrobiologii, 54 (4), 344, 2015 [in Polish].

16. OGÓREK R., KALINOWSKA K., PLĄSKOWSKA E., BARAN E., MOSZCZYŃSKA E. Mycological air pollutions on different culture mediums in selected rooms of dermatology department. Part I. Mikologia Lekarska, 18 (1), 30, 2011 [In Polish]

17. OGÓREK R., KALINOWSKA K., PLĄSKOWSKA E., BARAN E., MATKOWSKI K. Mycological air pollutions on different culture mediums in selected rooms of dermatology department. Part II. Mikologia Lekarska, 18 (1), 83, 2011 [In Polish].

18. LITTMAN M.L. A culture medium for the primary isolation of fungi. Science, 106 (2744), 109, 1947.

19. KAISER K., WOLSKI A. Inspection of microbiology cleanness of air. Technika Chłodnicza i Klimatyzacyjna, 4, 158, 2007 [In Polish].

20. OGÓREK R., KOZAK B., VIŠŇOVSKÁ Z., TANČINOVÁ D. Phenotypic and genotypic diversity of airborne fungal spores in Demänovská Ice Cave (Low Tatras, Slovakia). Aerobiologia, 34 (1), 13, 2018.

21. ŻUKIEWICZ-SOBCZAK W.A., SOBCZAK P., KRASOWSKA E., ZWOLIŃSKI J., CHMIELEWSKABADORA J., GALINSKA E. Allergenic potential of moulds isolated from buildings. Annals of Agricultural and Environmental Medicine, 20 (3), 500, 2013.

22. SANDOVAL-DENIS M., SUTTON D.A., MARTINVICENTE A., CANO-LIRA J.F., WIEDERHOLD N., GUARRO J., GENÉ J. Cladosporium species recovered from clinical samples in the United States. Journal of Clinical Microbiology, 53 (9), 2990, 2015.
23. SHARPE R.A., BEARMAN N., THORNTON C.R., HUSK K., OSBORNE N.J. Indoor fungal diversity and asthma, a meta-analysis and systematic review of risk factors. Journal of Allergy and Clinical Immunology, 135 (1), 110, 2015

24. WHO, WHO guidelines for indoor air quality, dampness and mould. Heseltine E., Rosen J. ed., Geneva, Switzerland, World Health Organization pp. 7-61, 2009.

25. HEATON P.E., CALLOW M.E., BUTLER G.M., MILNE A. Control of mould growth by anti-fungal paints. International Biodeterioration, 27 (2), 163, 1991.

26. DYLĄG M., SAWICK A., OGÓREK R. Diversity of Species and Susceptibility Phenotypes toward Commercially Available Fungicides of Cultivable Fungi Colonizing Bones of Ursus spelaeus on Display in Niedźwiedzia Cave (Kletno, Poland). Diversity, 11, 224, 2019.

27. PEDERSEN IB.O. Method for preventing and combating fungus attack in existing building structures and electrodes for carrying out the method. United States Patent, 5442876, http,//www.freepatentsonline.com/5442876.html. 1995.

28. CHOI Y.W., HYDE K.D., HO W.H. Single spore isolation of fungi. Fungal Diversity, 3, 29, 1999.

29. NEJADKOORKI F. Current air quality issues. InTech, 498, 2015.

30. RICHARDSON M., BOWYER P., SABINO R. The humanlung and Aspergillus, You are what you breathe in? Medical Mycology, 57 (2), S145, 2019.

31. PERRONE G., SUSCA A. Penicillium species and their associated mycotoxins. Methods in Molecular Biology, 1542, 107, 2017.

32. SABINO R., VERÍSSIMO C., VIEGAS C., VIEGAS S. BRANDÃOM J, ALVES-CORREIA M., BORREGO L.M., CLEMONS K.V., STEVENS D.A., RICHARDSON M. The role of occupational Aspergillus exposure in the development of diseases. Medical Mycology, 57 (2), S196, 2019.

33. DOUWES J., THORNE P., PEARCE N., HEEDERIK D. Bioaerosol health effects and exposure assessment, progress and prospects. The Annals of Occupational Hygiene, 47 (3), 187, 2003.

34. EDUARD W. Fungal spores, a critical review of the toxicological and epidemiological evidence as a basis for occupational exposure limit setting. Critical Reviews in Toxicology, 39 (10), 799, 2009. 